\title{
Arquitectura y urbanismo valenciano en el franquismo (1939-1975)
}

\author{
PATUEL, Pascual \\ Universitat de València, Valencia, 2020 \\ ISBN: 978-84-9134-679-1
}

Las publicaciones sobre las dictaduras europeas han sido numerosas a lo largo del siglo XXI, siendo significativos los títulos dedicados a las manifestaciones artísticas producidas en esas etapas de la historia más reciente. Por lo que respecta al caso español, el libro que nos ocupa es un claro ejemplo de esta práctica. Así, con Arquitectura y urbanismo valenciano en el franquismo (1939-1975) se incorpora un nuevo estudio dedicado a estas cuestiones, algo que, de manera acertada, ya se había realizado en las ciudades de Palma de Mallorca, Bilbao, Santander, Almería, Segovia, Badajoz, Zamora, Salamanca y Madrid y que, en esta ocasión, tiene el mérito añadido de abarcar a una comunidad autónoma.

Este libro responde a un riguroso trabajo a cargo de Pascual Patuel Chust, catedrático de Historia del Arte de la Universidad de Valencia, basado en una profunda y cuidadosa revisión legislativa, bibliográfica, hemerográfica y documental de la que destaca como resultado la incorporación de información novedosa hallada en los archivos de la Comunidad Valenciana. En el texto, Patuel Chust reflexiona y analiza la producción arquitectónica promovida durante los treinta y nueve años de autarquía en la citada autonomía con la voluntad de, como él mismo afirma, «llevar a cabo una reconstrucción diacrónica de toda la problemática» que recoge el título. Con esta idea, el autor ha escogido un criterio cronológico para ordenar el contenido del libro, dividiéndolo en dos períodos. El primero, que comprende entre 1939 y 1953 , corresponde con el predominio de un tipo de arquitectura de marcado sabor historicista, tendencia marcada desde el gobierno central. El segundo, que se dilata desde mediados de la década de 1950 hasta el fin de la dictadura en 1975, se caracteriza por la apertura internacional de nuestro país y, con ella, el desarrollo de un acercamiento a la vanguardia fuertemente influido por el Movimiento Moderno. Además, en cada uno de estos bloques, Pascual Patuel ha establecido unos

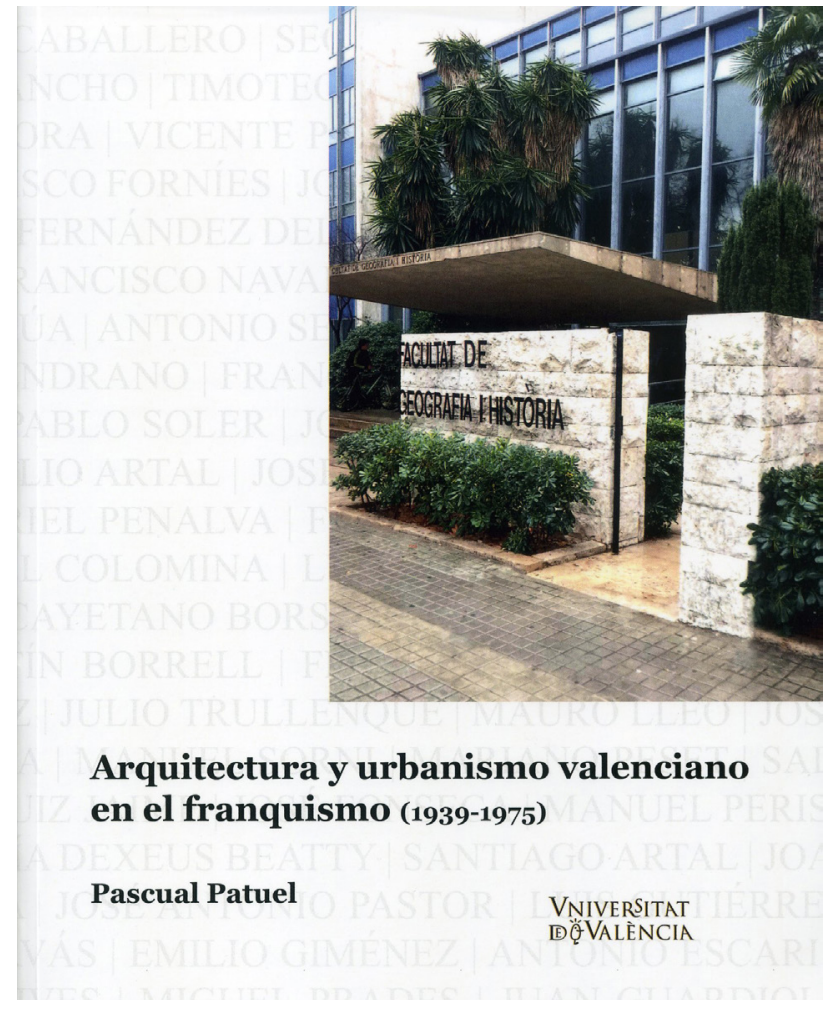

epígrafes dedicados, por un lado, al estudio de los planes de urbanismo redactados y aplicados en esos años y, por otro, a la investigación de la arquitectura proyectada en aquella época según cada tipología concreta, la de la vivienda, la escolar, la religiosa y los complejos vacacionales.

Por lo que respecta al análisis arquitectónico y urbanístico de las obras recogidas en la publicación, hay que señalar que, geográficamente, el estudio comprende toda la Comunidad Valenciana, lo cual corrobora el ingente trabajo de campo realizado. En esta tarea, el autor aborda de manera didáctica y ágil el devenir de una de las principales

Cómo citar este artículo: NÚÑEZ IZQUIERDO, Sara, "PATUEL, Pascual: Arquitectura y urbanismo valenciano en el franquismo (1939-1975)", Boletín de Arte-UMA, n. 42, Departamento de Historia del Arte, Universidad de Málaga, 2021, pp. 321-322, ISSN: 0211-8483, e-ISSN: 2695-415X, DOI: http://dx.doi.org/10.24310/BoLArte.2021.vi42.12030 
autonomías de la península ibérica, que en esos años pasó de ser una zona de notable actividad agraria a otra industrializada y pionera en el desarrollo del turismo.

A medida que se pasan las páginas del libro, se confirma el indudable valor del conjunto de inmuebles objeto de interés y, en algunos casos, digno de un nivel de protección del que aún no gozan. Otra de las importantes aportaciones de este volumen es la recuperación de los nombres de los arquitectos que proyectaron este patrimonio arquitectónico tan variado y numeroso de los que apenas se tenía noticia hasta la fecha, caso de Francisco Javier Goerlich Lleó, Luis Albert Ballester, Vicente Traver Tomás, Fernando Moreno Barberá, Miguel Colomina Barberá, entre otros, junto a los que figuran nombres sobradamente conocidos del panorama arquitectónico español como Luis Gutiérrez Soto, Miguel Fisac Serna, Julio Cano Lasso, José Antonio Corrales y Ramón Vázquez Molezún.

El autor de este trabajo ha consultado abundante documentación custodiada en numerosos archivos emplaza- dos en la capital valenciana, Alicante y Castellón de la Plana, tales como los municipales, los históricos provinciales, los universitarios, además del de la Real Academia de Bellas Artes de San Carlos de Valencia y el Archivo Diocesano de Valencia, aparte de otros privados.

En conclusión, podemos considerar que Arquitectura y urbanismo valenciano en el franquismo (1939-1975) constituye una aportación trascendental al estudio de la arquitectura valenciana y española del siglo XX. El libro se distingue por su atractivo diseño y la calidad de las fotografías y es, sin duda alguna, interesante por su acertado enfoque del tema estudiado, además de las cuestiones planteadas, la importancia de la novedosa documentación aportada, así como el desglose de la extensa bibliografía, hacen de él un libro de consulta obligatoria dentro de los estudios de este ámbito.

Sara Núñez Izquierdo Universidad de Salamanca 